\title{
Transient Convection Fluid Flow with Heat Flux in an Infinite Vertical Plate with Chemical Mass Transfer
}

\author{
I.J. Uwanta \\ MAN, NMS, NAMP \\ Department of Mathematics, \\ Usmanu Danfodiyo University, Sokoto-Nigeria
}

\author{
Murtala Sani \\ MAN, NMS, ICMCS \\ Department of Mathematics \& Computer Science, \\ Umaru Musa Yar'adua University, Kasina-Nigeria
}

\begin{abstract}
The paper studied the transient convection fluid flow with heat flux in an infinite vertical plate with chemical mass transfer. The dimensionless governing equations were solved using the Laplace transform method to obtained the analytical expressions of velocity, temperature and concentration profiles of the fluid with expression of Skin friction, mass and heat transfer in terms of Shear stress, Nusselt number and Sherwood number respectively. The effects of various parameters associated with flow like Prandtl number Pr, Schmidt number Sc, modified Grashof number N, Radiation parameter $\mathrm{F}$, chemical reaction parameter $\mathrm{K}$, and time $\mathrm{t}$ are studied with the help of graphs and tables. It is observed that the velocity decreases with increasing $\mathrm{Pr}, \mathrm{N}$ and $\mathrm{t}$, and temperature increase with increasing $\mathrm{t}$ and $\mathrm{N}$ and decrease with increasing $\mathrm{Pr}$, While the concentration increase with increasing $\mathrm{Sc}, \mathrm{K}$ and $\mathrm{t}$.
\end{abstract}

\section{Keywords}

Transient, Heat flux, Chemical mass transfer and vertical plate.

\section{INTRODUCTION}

Several researchers have studied the problem of free convection flow with mass transfer. Acharya et al [1] have investigated the effect of chemical and thermal diffusion with Hall current on unsteady hydromagnetic flow near an infinite vertical porous plate. Chandran et al [2] have discussed the unsteady free convection flow with heat flux and accelerated motion. Das et al [3] have studied the effects of mass transfer on the flow past impulsively started infinite vertical plate with constant heat flux and chemical reaction. Diffusion of a chemically reactive species from a stretching sheet is studied by Anderson et al [4]. Anjali Devi and Kandasamy [5] have analyzed the effects of chemical reaction, heat and mass transfer on laminar flow along a semi-infinite horizontal plate. Muthucumaraswamy and Ganesan [6] have studied the impulsive motion of a vertical plate with heat flux/mass flux/suction and diffusion of chemically reaction species. Muthucumaraswamy [7] has analyzed the effects of a chemical reaction on a moving isothermal vertical surface with suction. Ghaly and Seddeek [8] have discussed the Chebyshev finite difference method for the effects of chemical reaction, heat and mass transfer on laminar flow along a semi-infinite horizontal plate with temperature dependent viscosity. Kandasamy et al [9] studied effects of chemical reaction, heat and mass transfer along a wedge with heat source and concentration in the presence of suction or injection, and chemical reaction, heat and mass transfer on MHD flow over a vertical stretching surface with heat source and thermal stratification effects. Mohamed et al [10] have discussed the finite element method for the effect of a chemical reaction on hydromagnetic flow and heat transfer of a heat generation fluid over a surface embedded in a nonDarcian porous medium. Anjali Devi and Kandasamy [11] have analyzed the effects of chemical reaction, heat and mass transfer on MHD flow past a semi infinite plate. The flow and mass transfer on a stretching sheet with a magnetic field and chemically reactive species are examined by Takhar et al [12]. Raptis and Perdikis [13] have analyzed the effect of a chemical reaction of an electrically conducting viscous fluid on the flow over a nonlinearly (quadratic) semi-infinite stretching sheet in the presence of a constant magnetic field which is normal to the sheet. Seddeek [14] has studied the finite element for the effects of chemical reaction, variable viscosity, thermophoresis, and heat generation/absorption on a boundary layer hydromagnetic flow with heat and mass transfer over a heat source. Unsteady laminar free convection past an infinite vertical plate for Prandtl number $\operatorname{Pr}=1.0$ in case of a step change in wall temperature with time was derived by Illingworth [15] and for $\operatorname{Pr} \neq 1.0$, he derived the solution in integral form. Soundalgekar [16] first presented an exact solution to the flow of a viscous incompressible fluid past an impulsively started infinite vertical plate by Laplace transform technique. The unsteady free convection flow with heat flux and accelerated boundary condition was investigated by Chandran et al [17]. Das et al [18] analyzed the flow problem with periodic temperature variation and Muthucumaraswamy [19] considered the natural convection with variable surface heat flux. Singh et al [20] have studied the transient free convection flow of a viscous incompressible fluid in a vertical parallel plate channel when the walls are heated asymmetrically. Narahari et al [21] have studied the transient free convection flow between two vertical parallel plates with constant heat flux at one boundary and the other maintained at a constant temperature. Jha et al [22] have studied the transient free convection flow in a vertical channel as a result of symmetric heating of the channel walls. More exciting, Rajesh and Vijaya [23] studied the chemical reaction effects on free convection flow past an exponentially accelerated vertical plate.

The present work will consider as an extension of Rajesh and Vijaya [23], the effect of radiation parameter in the energy equation.

\section{PROBLEM FORMULATION}

The unsteady flow of a viscous incompressible fluid past an infinite vertical plate with heat flux and mass diffusion is considered. It is assumed that the effect of viscous dissipation is negligible in the energy equation and there is a first order chemical reaction between the diffusing species and the fluid. 
The $x^{*}$-axis is taken along the plate in the vertically upward direction and the $y^{*}$-axis is taken normal to the plate. Initially the plate and the fluid are at the same temperature $T_{\infty}^{*}$ in the stationary condition with concentration level $C_{\infty}^{*}$ at all points. At time, $t^{*}>0$, the plate is exponentially accelerated with a velocity $u^{*}=U_{o} e^{a^{*} t^{*}}$ in its own plane and the temperature of the plate is raised at a uniform rate and the level of concentration near the plate is raised linearly with time. All the physical properties of the fluid are considered to be constant. The unsteady flow is governed by the following equations:

$$
\begin{aligned}
& \frac{\partial u^{*}}{\partial t^{*}}=v \frac{\partial^{2} u^{*}}{\partial y^{* 2}}+g \beta\left(T^{*}-T_{\infty}^{*}\right)+g \beta^{*}\left(C^{*}-C_{\infty}^{*}\right) \\
& \frac{\partial C^{*}}{\partial t^{*}}=D \frac{\partial^{2} C^{*}}{\partial y^{* 2}}-K^{*}\left(C^{*}-C_{\infty}^{*}\right) \\
& \frac{\partial T^{*}}{\partial t^{*}}=\frac{k}{\rho C_{\rho}} \frac{\partial^{2} T^{*}}{\partial y^{* 2}}-\frac{Q_{0}}{\rho C_{\rho}}\left(T^{*}-T_{\infty}^{*}\right)
\end{aligned}
$$

The initial and boundary conditions relevant to the fluid flow are:

$$
\left.\begin{array}{r}
t^{*} \leq 0: u^{*}=0, T^{*}=T_{\infty}^{*}, C^{*}=C_{\infty}^{*} \quad \text { For all } y^{*} \\
t^{*}>0: u^{*}=U_{o} e^{a^{*} t^{*}}, \frac{\partial T^{*}}{\partial y^{*}}=-\frac{q}{k}, C^{*}=C_{w}^{*} \text { at } y^{*}=0 \\
u^{*} \rightarrow 0, T^{*} \rightarrow T_{\infty}^{*}, C^{*} \rightarrow C_{\infty}^{*} \text { as } y^{*} \rightarrow \infty
\end{array}\right\}
$$

Where $u^{*}$ is the axial velocity, $t^{*}$ is time, $T^{*}$ the fluid temperature, $\beta$ is coefficient of volume, $C^{*}$ is the fluid concentration, $C_{w}^{*}$ is wall concentration, D the mass diffusivity, $\mathrm{K}$ is chemical reaction parameter, $\beta^{*}$ is the coefficient of concentration expansion.

\section{ANALYTICAL SOLUTION}

To solve the governing equations in dimensionless form, the following non-dimensional quantities were introduced:

$$
\begin{aligned}
& y=\frac{y^{*} U_{0}}{v}, U=\frac{u^{*}}{U_{0}}, t=\frac{t^{*} U_{0}^{2}}{v}, F=\frac{v Q_{0}}{\rho c_{\rho} U_{0}^{2}} \\
& \theta=\frac{T^{*}-T_{\infty}^{*}}{q \mathrm{v} / k}, c=\frac{C^{*}-C_{\infty}^{*}}{C_{w}^{*}-C_{\infty}^{*}}, a=\frac{a^{*} \mathrm{v}}{U_{0}^{2}}, \\
& K=\frac{\cup K^{*}}{U_{0}{ }^{2}}, S c=\frac{\mathrm{v}}{D}, \operatorname{Pr}=\frac{\mathrm{v} \rho c_{\rho}}{k}, \\
& G r=\frac{g \beta q v^{2}}{k U_{0}^{4}}, G c=\frac{g \beta^{*} v\left(C_{w}^{*}-C_{\infty}^{*}\right)}{U_{0}^{3}}
\end{aligned}
$$

The governing equations on using (5) into (1) to (4) reduce to the following

$$
\begin{aligned}
& \frac{\partial u}{\partial t}=\frac{\partial^{2} u}{\partial y^{2}}+\theta+N c \\
& \frac{\partial c}{\partial t}=\frac{1}{S c} \frac{\partial^{2} c}{\partial y^{2}}-K c \\
& \frac{\partial \theta}{\partial t}=\frac{1}{\operatorname{Pr}} \frac{\partial^{2} \theta}{\partial y^{2}}-F \theta
\end{aligned}
$$

Subject to the boundary conditions

For $t \leq 0: u=\theta=c=0$, for $0 \leq y \leq 1$

For $t>0: u=e^{a t}, \frac{\partial \theta}{\partial y}=-1, c=1$ at $y=0$

$$
u \rightarrow 0, \theta \rightarrow 0, c \rightarrow 0, \text { as } y \rightarrow \infty
$$

To obtain the solutions, we apply the Laplace transform to (6) $-(8)$ and the boundary conditions to get

$$
\begin{aligned}
& \frac{d^{2} \theta}{d y^{2}}-\operatorname{Pr}(P+F) \theta=0 \\
& \frac{d^{2} C}{d y^{2}}-S c(P+K) C=0 \\
& \frac{d^{2} U}{d y^{2}}-P U=-\theta-N C
\end{aligned}
$$

The boundary conditions are

$$
\left.\begin{array}{c}
t \leq 0: U=\theta=C=0, \forall 0 \leq y \leq 1 \\
t>0: U=\frac{1}{P-a}, \frac{d \theta}{d y}=-\frac{1}{P}, C=\frac{1}{P}, \text { at } y=0 \\
U \rightarrow 0, \theta \rightarrow 0, C \rightarrow 0, \text { as } y \rightarrow \infty
\end{array}\right\}
$$

The solutions to (9) to (11) subject to (12) give

$$
\begin{aligned}
& \theta(y, p)=\frac{e^{-k_{1} y \sqrt{Z}}}{\sqrt{\operatorname{Pr}}(Z-F) \sqrt{Z}} \\
& C(y, p)=\frac{e^{-k_{2} \sqrt{Z}}}{Z-K}
\end{aligned}
$$


$U(y, p)=\frac{1}{(\operatorname{Pr}-1) \sqrt{\operatorname{Pr}}}\left[\frac{e^{-y \sqrt{P}}}{b \sqrt{b+F}(P-b)}\right.$

$-\frac{e^{-y \sqrt{P}}}{b \sqrt{F} P}-\frac{e^{-y \sqrt{P}}}{F(b+F) \sqrt{P+F}}-\frac{e^{-y \sqrt{\operatorname{Pr}} \sqrt{P+F}}}{b \sqrt{b+F}(P-b)}$

$\left.+\frac{e^{-y \sqrt{\operatorname{Pr}} \sqrt{P+F}}}{b \sqrt{F} P}+\frac{e^{-y \sqrt{\operatorname{Pr}} \sqrt{P+F}}}{F(b+F) \sqrt{P+F}}\right]+\frac{N}{(S c-1) c_{1}} \times$

$\left[\frac{e^{-y \sqrt{P}}}{P-c_{1}}-\frac{e^{-y \sqrt{P}}}{P}-\frac{e^{-y \sqrt{S c} \sqrt{P+K}}}{p-c_{1}}+\frac{e^{-y \sqrt{S c} \sqrt{P+K}}}{P}\right]$

$\left.+\frac{e^{-y \sqrt{P}}}{P-a}\right\}$

The Laplace inversions of (13), (14) and (15) yield the following

$$
\begin{aligned}
& \theta(y, t)=\frac{1}{\sqrt{\operatorname{Pr}}}\left\{\frac{e^{F t}}{2 \sqrt{F}}\left[e^{-k_{1} \sqrt{F}} \operatorname{erfc}\left(\frac{k_{1}}{2 \sqrt{t}}-\sqrt{F t}\right)\right]\right. \\
& \left.+e^{k_{1} \sqrt{F}} \operatorname{erfc}\left(\frac{k_{1}}{2 \sqrt{t}}+\sqrt{F t}\right)-\frac{e^{-\frac{y^{2} \operatorname{Pr}}{4 t}}}{F \sqrt{\pi t}}\right\} \\
& c(y, t)=\frac{e^{K t}}{2}\left\{e^{-k_{2} \sqrt{K}} \operatorname{erfc}\left(\frac{k_{2}}{2 \sqrt{t}}-\sqrt{K t}\right)\right. \\
& \left.+e^{k_{2} \sqrt{K}} \operatorname{erfc}\left(\frac{k_{2}}{2 \sqrt{t}}+\sqrt{K t}\right)\right\}
\end{aligned}
$$

And,

$$
\begin{aligned}
& u(y, t)=\frac{1}{(\operatorname{Pr}-1) \sqrt{\operatorname{Pr}}}\left[\frac { e ^ { b t } } { 2 b \sqrt { b + F } } \left\{e^{-y \sqrt{b}} \operatorname{erfc} \times\right.\right. \\
& \left.\left(\frac{y}{2 \sqrt{t}}-\sqrt{b t}\right)+e^{y \sqrt{b}} \operatorname{erfc}\left(\frac{y}{2 \sqrt{t}}+\sqrt{b t}\right)\right\} \\
& -\frac{1}{b \sqrt{F}}\left\{\operatorname{erfc}\left(\frac{y}{2 \sqrt{t}}\right)\right\}-\frac{1}{F(b+F)}\left\{e^{-\{y \sqrt{-F}+F t\}}\right\} \\
& -\frac{e^{d t}}{2 b \sqrt{b+F}}\left\{e^{-k_{1} \sqrt{d}} \operatorname{erfc}\left(\frac{k_{1}}{2 \sqrt{t}}-\sqrt{d t}\right)\right. \\
& \left.+e^{k_{1} \sqrt{d}} \operatorname{erfc}\left(\frac{k_{1}}{2 \sqrt{t}}+\sqrt{d t}\right)\right\}+\frac{e^{F t}}{2 b \sqrt{F}}\left\{e^{-k_{1} \sqrt{F}} \operatorname{erfc} \times\right. \\
& \left(\frac{k_{1}}{2 \sqrt{t}}-\sqrt{F t}\right)+e^{k_{1} \sqrt{F}} \operatorname{erfc}\left(\frac{k_{1}}{2 \sqrt{t}}+\sqrt{F t}\right)
\end{aligned}
$$

$$
\begin{aligned}
& +\frac{e^{-F t}}{F(b+F)}+\frac{N}{(S c-1) c_{1}}\left[\frac { e ^ { c _ { 1 } t } } { 2 } \left\{e^{-y \sqrt{c_{1}}} \operatorname{erfc} \times\right.\right. \\
& \left.\left(\frac{y}{2 \sqrt{t}}-\sqrt{c_{1} t}\right)+e^{y \sqrt{c_{1}}} \operatorname{erfc}\left(\frac{y}{2 \sqrt{t}}+\sqrt{c_{1} t}\right)\right\} \\
& -\operatorname{erfc}\left(\frac{y}{2 \sqrt{t}}\right)-\frac{e^{f t}}{2}\left\{e^{-k_{2} \sqrt{f}} \operatorname{erfc}\left(\frac{k_{2}}{2 \sqrt{t}}-\sqrt{f t}\right)\right. \\
& \left.+e^{k_{2} \sqrt{f}} \operatorname{erfc}\left(\frac{k_{2}}{2 \sqrt{t}}+\sqrt{f t}\right)\right\}+\frac{e^{K t}}{2}\left\{e^{-k_{2} \sqrt{K}} \times\right. \\
& \left.\operatorname{erfc}\left\{\left(\frac{k_{2}}{2 \sqrt{t}}-\sqrt{K t}\right)+e^{k_{2} \sqrt{K}} \operatorname{erfc}\left(\frac{k_{2}}{2 \sqrt{t}}+\sqrt{K t}\right)\right\}\right] \\
& +\frac{e^{a t}}{2}\left\{e^{-y \sqrt{a}} \operatorname{erfc}\left(\frac{y}{2 \sqrt{t}}-\sqrt{a t}\right)+e^{y \sqrt{a}} \operatorname{erfc} \times\right. \\
& \left.\left(\frac{y}{2 \sqrt{t}}+\sqrt{a t}\right)\right\}
\end{aligned}
$$

Where:

$$
k_{1}=y \sqrt{\operatorname{Pr}} ; k_{2}=y \sqrt{S c} ; c_{1}=\frac{K S c}{1-S c} ; d=\frac{\operatorname{Pr} F}{1-\operatorname{Pr}}
$$

The Skin friction from the velocity is given by

$$
\begin{array}{r}
\left.\frac{\partial u}{\partial y}\right|_{y=0}=\frac{1}{(\operatorname{Pr}-1) \sqrt{\operatorname{Pr}}}\left[\frac { e ^ { b t } } { b \sqrt { b + F } } \left\{\operatorname{erfc}\left(\frac{1}{2 \sqrt{t}}\right)\right.\right. \\
+\sqrt{b} \operatorname{erfc}(\sqrt{b t})\}-\frac{1}{b \sqrt{F}}\left\{\operatorname{erfc}\left(\frac{1}{2 \sqrt{t}}\right)\right\}
\end{array}
$$$$
+\frac{\sqrt{-F}}{F(b+F)}-\frac{e^{d t}}{b \sqrt{b+F}}\left\{\operatorname{erfc}\left(\frac{\sqrt{\operatorname{Pr}}}{2 \sqrt{t}}\right)\right.
$$$$
+\sqrt{\operatorname{Pr}} \sqrt{d} \operatorname{erfc}(\sqrt{d t})\}+\frac{e^{F t}}{b \sqrt{F}}\left\{\operatorname{erfc}\left(\frac{\sqrt{\mathrm{Pr}}}{2 \sqrt{t}}\right)\right.
$$$$
+\sqrt{\operatorname{Pr}} \sqrt{F} \operatorname{erfc}(\sqrt{F t})\}]+\frac{N}{(S c-1) c_{1}} e^{c_{1} t} \times
$$$$
\left\{\operatorname{erfc}\left(\frac{1}{2 \sqrt{t}}\right)+\sqrt{c_{1}} \operatorname{erfc}\left(\sqrt{c_{1} t}\right)\right\}-\operatorname{erfc}\left(\frac{1}{2 \sqrt{t}}\right)
$$ 


$$
\begin{aligned}
& -e^{f t}\left\{\operatorname{erfc}\left(\frac{\sqrt{S c}}{2 \sqrt{t}}\right)+\sqrt{S c} \sqrt{f} \operatorname{erfc}(\sqrt{f t})\right\}+e^{K t} \times \\
& \left.\left\{\operatorname{erfc}\left(\frac{\sqrt{S c}}{2 \sqrt{t}}\right)+\sqrt{S c} \sqrt{K} \operatorname{erfc}(\sqrt{K t})\right\}\right] \\
& +e^{a t}\left\{\operatorname{erfc}\left(\frac{1}{2 \sqrt{t}}\right)+\sqrt{a} \operatorname{erfc}(\sqrt{a t})\right\}
\end{aligned}
$$

Similarly, the Nusselt number become

$$
\begin{gathered}
\left.\frac{\partial \theta}{\partial y}\right|_{y=0}=\frac{e^{F t}}{\sqrt{\operatorname{Pr}} \sqrt{F}}\left\{\operatorname{erfc}\left(\frac{\sqrt{\operatorname{Pr}}}{2 \sqrt{t}}\right)\right. \\
+\sqrt{\operatorname{Pr}} \sqrt{F} \operatorname{erfc}(\sqrt{F t})\}
\end{gathered}
$$

While the Sherwood number is

$$
\left.\frac{\partial c}{\partial y}\right|_{y=0}=e^{K t}\left\{\operatorname{erfc}\left(\frac{\sqrt{S c}}{2 \sqrt{t}}\right)+\sqrt{S c} \sqrt{K} \operatorname{erfc}(\sqrt{K t})\right\}
$$

\section{RESULTS AND DISCUSSIONS}

From the analytical solutions, the numerical solutions for different values of the Prandtl number Pr, Schmidt number Sc, radiation parameter $\mathrm{F}$, modified Grashof number $\mathrm{N}$ and chemical reaction parameter $\mathrm{K}$ were obtained. The following parameters values are fixed throughout the computation, $\operatorname{Pr}=$ $0.71, \mathrm{~N}=0.1, \mathrm{a}=0.2, \mathrm{t}=0.1, \mathrm{y}=0: 0.02: 40, \mathrm{Sc}=0.2, \mathrm{~K}=$ $0.5, \mathrm{~F}=0.5$.

Figures 1 to 9 are for the analytical solutions.

The temperature profiles are illustrated in Figures 1 to 3 for different values of Prandtl number $(\operatorname{Pr}=0.60,0.71,0.85,1)$, time $(\mathrm{t}=1,2,3,4)$ and radiation parameter $(\mathrm{F}=1,1.1,1.2$, 1.3) shown in Figures 1, 2 and 3 respectively. In Figure 1, it's observed that, the temperature decreases with increase in the Prandtl number. Figure 2 reveals that, the temperature increase with respect to increase in time. Similarly, Figure 3 shows that the temperature increase with increase of the radiation parameter.

The concentration profiles are presented in Figures 4 to 6 for different values of Schmidt number ( $\mathrm{Sc}=0.2,0.4,0.6,0.8$ ), time $(\mathrm{t}=1,2,3,4)$ and the chemical reaction parameter $(\mathrm{K}=$ 1, 1.1, 1.2, 1.3). In Figure 4, it's noticed that the concentration increase with increase in the Schmidt number. Figure 5 indicates that increase in time increase the concentration. Similarly, Figure 6 shows that the concentration increase as the chemical reaction parameter increase.

The velocity profiles have been studied and presented in Figures 7 to 9 with different values of radiation parameter ( $F$ $=0.02,0.04,0.06,0.08)$, Prandtl number $(\operatorname{Pr}=0.025,0.60$, $0.71,0.85)$ and $(\mathrm{a}=0.1,0.2,0.3,0.4)$. Figure 7 reveals that the velocity decreases with increase in the radiation parameter. Similarly, Figure 8 shows that the velocity decrease with increase in the Prandtl number. While in Figure 9 , it's noticed that, there is a slight increase in velocity with increase in the value of a.

Tables 1 to 5 are the tables for Skin friction, Nusselt number and Sherwood number for the analytical solution.

The Skin frictions are illustrated in Tables 1 to 3 for different values of modified Grashof number $(\mathrm{N}=0.1,0.11,0.21)$ and frequency of oscillation $(\mathrm{a}=0.1,0.2,0,3)$, Prandtl number $(\mathrm{Pr}$ $=0.60,0.71,0.85)$ and radiation parameter $(\mathrm{F}=0.02,0.04$, $0.06)$, and Schmidt number $(\mathrm{Sc}=0.2,0.4,0.6)$ and chemical reaction parameter $(\mathrm{K}=1.0,1.1,1.2)$ shown in Tables 1,2 and 3 respectively. In Table 1, it's observed that the Skin friction is decreasing with increasing modified Grashof number while increase in the frequency of oscillation leads to increase in the Skin friction. Table 2 shows that as the Prandtl number increase, the Skin friction also increase but the Skin friction decrease with increase in the radiation parameter. Furthermore, Table 3 indicates that the Skin friction decrease whenever the Schmidt number increase and increase in the chemical reaction parameter results to decrease in the Skin friction.

Table 4 shows that increasing Prandtl number leads to decrease of Nusselt number. Similarly, increase of the radiation parameter results to decrease of the Nusselt number. While Table 5 indicates that increase in Schmidt number and chemical reactions parameter increase the Sherwood number.

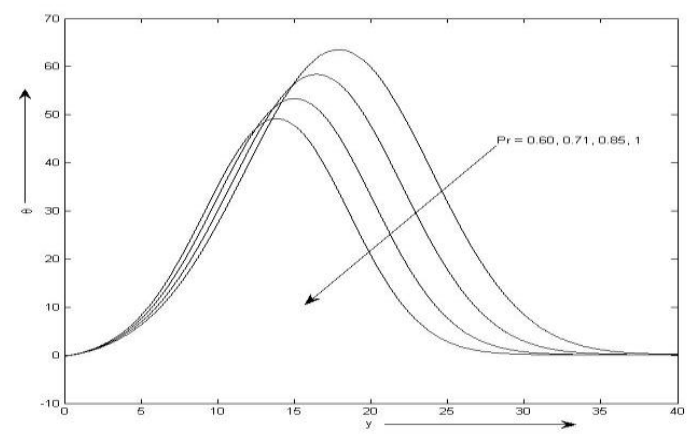

Figure 1: Variation of Temperature against y for different values of Pr.

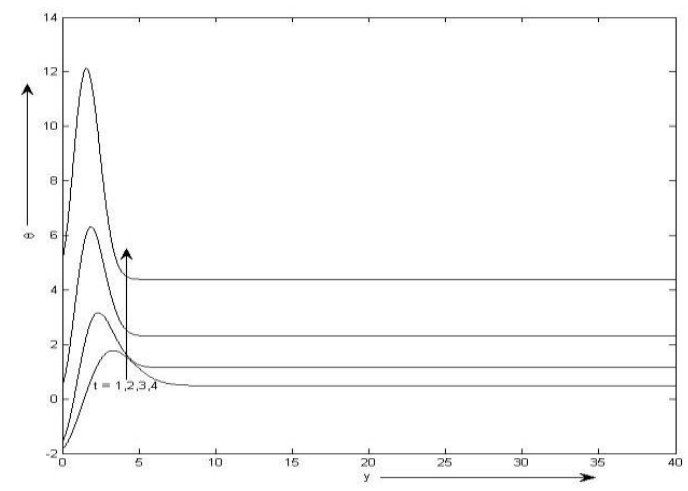

Figure 2: Variation of Temperature against $y$ for different values of $t$. 


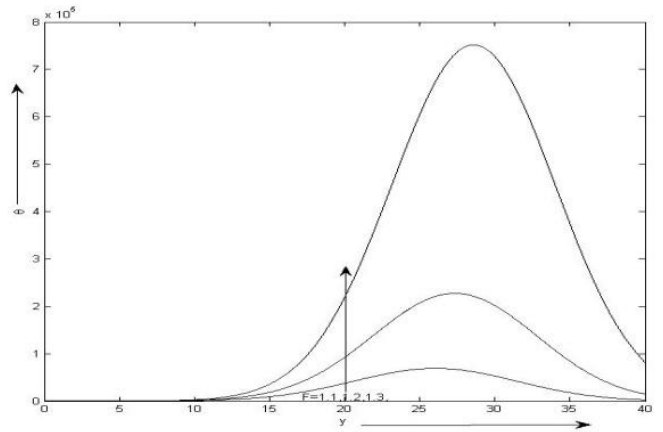

Figure 3: Variation of Temperature against $y$ for different values of $\mathbf{F}$.

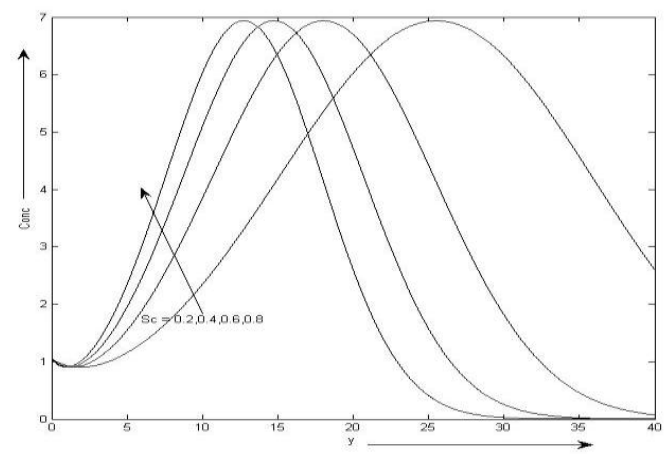

Figure 4: Variation of Concentration against $y$ for different values of Sc.

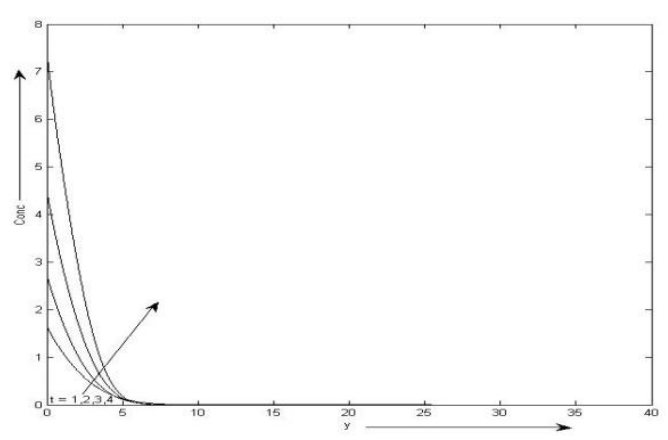

Figure 5: Variation of Concentration against y for different values of $t$.

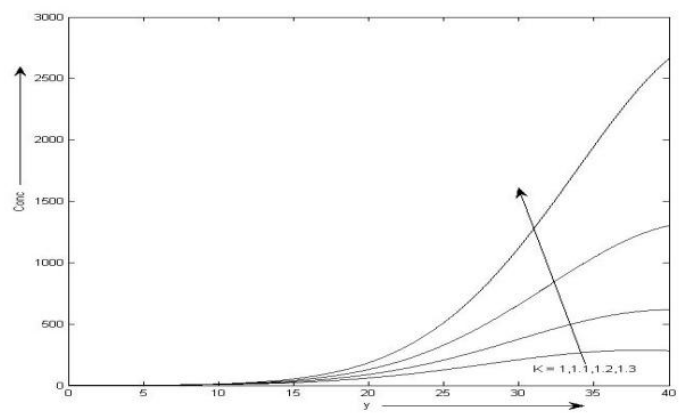

Figure 6: Variation of Concentration against y for different values of $K$.

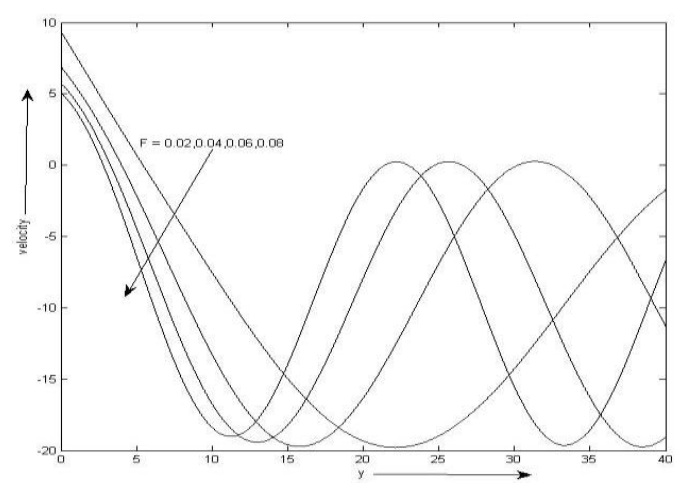

Figure 7: Variation of Velocity against y for different values of $\mathbf{F}$.

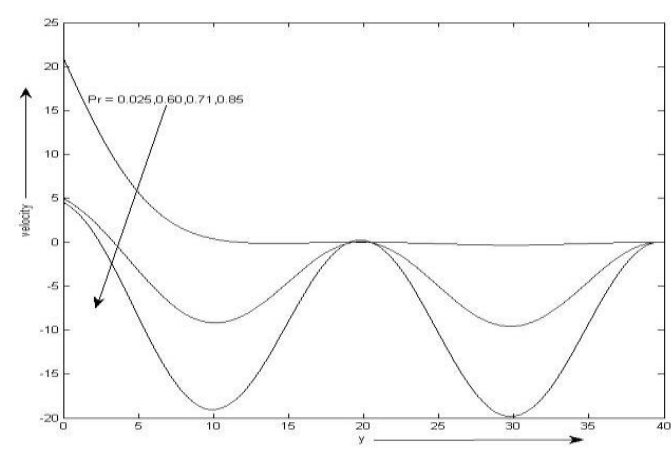

Figure 8: Variation of Velocity against $y$ for different values of Pr.

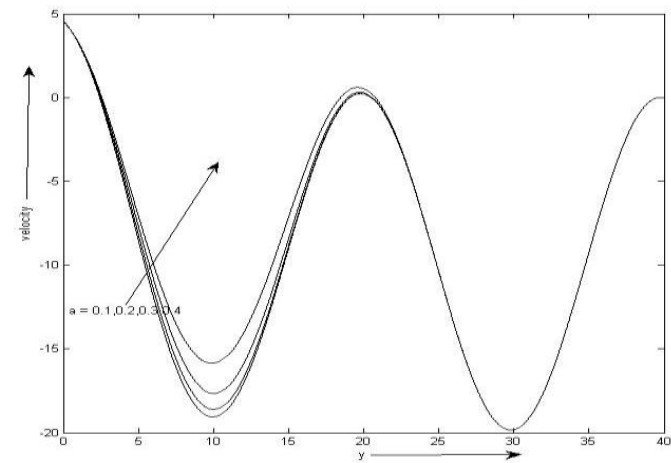

Figure 9: Variation of Concentration against $y$ for different values of $\mathbf{a}$.

Table 1: Skin Friction for different values of $\mathbf{N}$ and a.

\begin{tabular}{|c|c|c|c|}
\hline $\mathrm{N}$ & 0.1 & 0.11 & 0.21 \\
\hline A & & & \\
\hline 0.1 & 0.7379 & 0.7374 & 0.7329 \\
\hline 0.11 & 0.8466 & 0.8462 & 0.8417 \\
\hline 0.21 & 0.9264 & 0.9259 & 0.9214 \\
\hline
\end{tabular}


Table 2: Skin Friction for different values of $\operatorname{Pr}$ and F.

\begin{tabular}{|c|c|c|c|}
\hline Pr & 0.60 & 0.71 & 0.85 \\
\hline F & & & \\
\hline & & & \\
\hline 0.02 & 2.4854 & 3.0350 & 4.5147 \\
& & & \\
\hline 0.04 & 2.2583 & 2.6740 & 3.6011 \\
& & & \\
\hline 0.06 & 2.1107 & 2.4314 & 2.9857 \\
& & & \\
\hline
\end{tabular}

Table 3: Skin Friction for different values of Sc and $\mathrm{K}$.

\begin{tabular}{|c|c|c|c|}
\hline Sc & 0.2 & 0.4 & 0.6 \\
& & & \\
\hline \multicolumn{1}{|c|}{ SF } & & & \\
& & & \\
\hline 1.0 & 2.5477 & 2.4896 & 2.3171 \\
& & & \\
\hline 1.1 & 2.5342 & 2.4813 & 2.2857 \\
\hline 1.2 & 2.5323 & 2.4729 & 2.2536 \\
& & & \\
\hline
\end{tabular}

Table 4: Nusselt number for different values of $\operatorname{Pr}$ and $F$.

\begin{tabular}{|c|c|c|c|}
\hline Pr & 0.60 & 0.71 & 0.85 \\
& & & \\
\hline $\mathrm{Fu}$ & & & \\
& & & \\
\hline 0.02 & 8.8407 & 8.1034 & 7.3813 \\
& & & \\
\hline 0.04 & 6.5221 & 5.9998 & 5.4881 \\
& & & \\
\hline 0.06 & 5.4913 & 5.0640 & 4.6454 \\
& & & \\
\hline
\end{tabular}

Table 6: Sherwood number for different values of Sc and

\begin{tabular}{|c|c|c|c|}
\hline \multicolumn{4}{|c|}{ K. } \\
\hline $\mathrm{Sc}$ & 0.2 & 0.4 & 0.6 \\
\hline & & & \\
\hline $\mathrm{K}$ & & & \\
\hline 1.0 & 1.0564 & 1.4385 & 1.5137 \\
\hline 1.1 & 1.3619 & 1.4639 & 1.5423 \\
\hline 1.2 & 1.3825 & 1.4883 & 1.5696 \\
\hline
\end{tabular}

\section{CONCLUSIONS}

The paper studied the transient convection fluid flow with heat flux in an infinite vertical plate with chemical mass transfer. The dimensionless governing equations were solved using the Laplace transform method. The effect of different parameters such as the Prandtl number, Schmidt number, radiation parameter and chemical reaction parameter were studied. The conclusion shows that:

- The concentration increase with increase in the Schmidt number, chemical reaction parameter and time.

- The velocity decrease with increasing Prandtl number, radiation parameter and frequency of oscillation.

- The temperature increase with increase in time and the radiation parameter while the temperature decrease with increasing Prandtl number.

\section{REFERENCES}

[1] Acharya, M., Dash, G. C. and Singh, L. P. 1995. Effect of chemical and thermal diffusion with Hall current on unsteady hydromagnetic flow near an infinite vertical porous plate. Journal of Applied Physics, 28, 2455-2464.

[2] Chandran, P., Sacheti, N. C. and Singh, A. K. 1998. Unsteady free convection flow with heat flux and accelerated boundary motion. Journal of Physics Society of Japan, 67, 124-129.

[3] Das, U. N., Deka, R. K. and Soundalgekar, V. M. 1994. Effects of mass transfer on flow past an impulsively started infinite vertical plate with constant heat flux and chemical reaction. Forschung im Ingenieurwesen, 60(10), 284-287.

[4] Andersson, H. I., Hansen, O. R. and Holmedal, B. 1994. Diffusion of a chemically reactive species from a stretching sheet. International Journal of Heat and Mass Transfer, 37(4), 659-664.

[5] Anjali, S. P. and Kandasamy, R. 1999. Effects of chemical reaction, heat and mass transfer on laminar flow along a semi infinite horizontal plate. Warme-und Stoffubertragung Zeitschrift, 35(6), 465-467. 
[6] Muthucumaraswamy, R. and Ganesan, P. 2000. On impulsive motion of a vertical plate with heat flux and diffusion of chemically reactive species. Forschung im Ingenieurwesen, 66(1), 17-23.

[7] Muthucumaraswamy, R. 2002. Effects of a chemical reaction on a moving isothermal vertical surface with suction. Journal Acta Mechanica, 155(1-2), 65-70.

[8] Ghaly, A. Y. and Seddeek, M. A. 2004. Chebyshev finite difference method for the effects of chemical reaction, heat and mass transfer on laminar flow along a semi infinite horizontal plate with temperature dependent viscosity. Journal of Chaos, Solitons and Fractals, 19(1), 61-70.

[9] Kandasamy, R., Periasamy, K. and Prabhu, K. S. 2005. Effects of chemical reaction, heat and mass transfer along a wedge with heat source and concentration in the presence of suction or injection. International Journal of Heat and Mass Transfer, 48(7), 1388-1394.

[10] Mohamed, R. A., Abbas, I. A. and Abo-Dahab, S. M. 2009. Finite element analysis of hydromagnetic flow and heat transfer of a heat generation fluid over a surface embedded in a non-Darcian porous medium in the presence of chemical reaction. Communications in Nonlinear Science and Numerical Simulation, 14(4), 1385-1395.

[11] Anjali, S. P. and Kandasamy, R. 2000. Effects of chemical reaction, heat and mass transfer on MHD flow past a semi infinite plate. Zeitschrift fur Angewandte Mathematik undMechanik, 80(10), 697-701.

[12] Takhar, H. S., Chamkha, A. J. and Nath, G. 2000. Flow and mass transfer on a stretching sheet with a magnetic field and chemically reactive species. International Journal of Engineering Science, 38(12), 1303-1314.

[13] Raptis, A. and Perdikis, C. 2006. Viscous flow over a non-linearly stretching sheet in the presence of a chemical reaction and magnetic field. International Journal of Non-Linear Mechanics, 41(4), 527-529.

[14] Seddeek, M. A. 2005. Finite element method for the effects of chemical reaction, variable viscosity, thermophores is and heat generation/absorption on a boundary layer hydromagnetic flow with heat and mass transfer over a heat surface. Journal Acta Mechanica, 177(1-4), 1-18.
[15] Illingworth, C. R. 1950. Unsteady laminar flow of gas near an infinite plate, Cambridge Philosopical Society, 44, 603-613.

[16] Soundalgekar, V. M. 1977. Free convection effects on Stokes problem for a vertical plate. Journal of Heat Transfer, 99c, 499-501.

[17] Chandran, P., Sacheti, N. C. and Singh, A. K. 1998. Unsteady free convection flow with heat flux and accelerated boundary motion. Journal of Physics Society of Japan, 67, 124-129.

[18] Das, U. N., Deka, R. K. and Soundalgekar, V. M. 1999. Transient free convection flow past an infinite vertical plate with periodic temperature variation. Journal of Heat Transfer, 121, 1091-1094.

[19] Muthucumaraswamy, R. 2004. Natural convection on flow past an impulsively started vertical plate with variable surface heat flux. Far East Journal of Applied Mathematics, 14, 99-109.

[20] Singh, A. K., Gholami, H. R. and Soundalgekar, V. M. 1996. Transient free convection flow between two vertical parallel plates. Journal of heat and Mass Transfer, 31, 329-331.

[21] Narahari, M., Sreenadh, S. and Soundalgekar, V. M. 2002. Transient free convection flow between long vertical parallel plates with constant heat flux at one boundary. Journal of Thermophysics and Aeromechanics, 9(2), 287-293.

[22] Jha, B. K., Singh, A. K. and Takhar, H. S. 2003. Transient free convection flow in a vertical channel due to symmetric heating. International Journal of Applied Mechanics and Engineering, 8(3), 497-502

[23] Rajesh, V. and Vijaya, S. Kumar Varma 2010. Chemical reaction effects on free convection flow past an exponentially accelerated vertical plate. International Journal of Engineering, 1, 1584-2665. 